\title{
Introducing a Learning Management System at a Russian University: Students' and Teachers' Perceptions
}

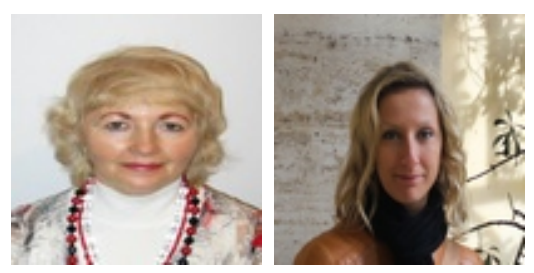

Natalya Emelyanova and Elena Voronina National Research University Higher School of Economics (HSE), Russian Federation

\section{Abstract}

Learning management systems (LMS) have been proven to encourage a constructive approach to knowledge acquisition and support active learning. One of the keys to successful and efficient use of LMS is how the stakeholders adopt and perceive this learning tool. The present research is therefore motivated by the importance of understanding teachers' and students' perceptions of LMS in order to anticipate possible issues (problems) and help to build a productive learning environment and a committed user community. The paper looks at this process at a Russian university (National Research University Higher School of Economics - HSE) where the system is being implemented and examines the following issues: qualification and readiness of the stakeholders to use LMS and their perceptions of the system's convenience, effectiveness, and usefulness. The research reveals remarkable divergence of students' and teachers' perceptions of various aspects of LMS which must be considered when raising the effectiveness of the system and building commitment to e-learning. They are analyzed and explicated in the present paper.

Keywords: Higher education; elearning; online learning; learning management systems; LMS 


\section{Introduction}

E-learning appeared at the end of the 20th century and has quickly become a new learning paradigm, having proved to be an effective educational technique (Alfadly, 2013; Boeker \& Klar, 2006; Mijatovic, Cudanov, Jednak, \& Kadijevich, 2012). It supports students' active involvement in the learning process and prepares the shift towards student-centered education. Effective e-learning enhances collaboration and communication thus encouraging group activities and a constructive approach to knowledge acquisition (Lin \& Hsieh, 2001). The growing use of online forms and systems of learning such as learning management systems (LMS) or virtual learning environments (VLE) and their rapid spreading are an appropriate response of higher education systems to current processes of integration and building of a global information society. This paper investigates the adoption, usage, and integration of an LMS at HSE by examining the perceptions of two stakeholder groups - students and teachers.

Teaching and learning through learning management systems (LMS) seems to be initially intended for distant education which is reasonable because online studies is the only way to acquire knowledge if you are far away from the learning environment. However, their usage may be extended to support face-to-face and blended delivery. In conditions where the number of contact hours is diminishing and there is a need to develop the learning skills of students the demand for using technology is increasing. It allows learners to perceive information at their own pace, and for teachers it can become a valuable tool to provide an individual approach and improve their existing teaching practices in general. Obviously, there are a lot of learning patterns and every student has their own ways of perceiving knowledge that cannot be effectively catered for in the classroom settings (Graf, 2007), so technology should enhance learning, meet different interests, and result in successful learning outcomes. Thus, educational institutions are striving to provide faculty with LMS and encourage its effective use.

\section{Literature Review}

The challenges that modern education should now respond to, including the degree of its virtualization, suitability for stakeholders, and the value of innovations, are now being discussed the world over. The body of works on LMS adoption and acceptance is constantly growing. The problem is being examined from different sides: administrative (Naveh, Tubin, \& Pliskin, 2010), faculty (Almarashdeh, Sahari, Zin, \& Alsmadi, 2011), and students (Naveh, Tubin, \& Pliskin, 2012).

Much of an elearning program success or failure can be attributed to how it is organized, managed, and adopted. Many researchers indicate a multidimensional character of the problem of learning management environments' perception, acceptance, and success. For instance, "critical success factors" (CSF) (Freund, 1988) have been grouped into several categories depending on the focus of the study: instructor, student, information technology, and university support (Selim, 2007); 
intellectual property, suitability of the course for an elearning environment, building the e-learning course, e-learning course content, e-learning course maintenance, elearning platform, and measuring the success of an e-learning course (Papp, 2000); student characteristics, student-student interaction, effective support, learning materials, learning environment, and information technology (Benigno \& Trentin, 2000); another conception (Volery \& Lord, 2000) identifies three groups of CSFs: technology, instructor and students' previous use of technology. Another study (Soong, Chan, Chua, \& Loh, 2001) names the following e-learning CSFs: human factors, technical competency of both instructor and student, e-learning mindset of both instructor and student, level of collaboration, and perceived information technology infrastructure.

The effectiveness and success of e-learning are determined by the skills and commitment of the instructor. It is believed that the effectiveness of e-learning depends not so much on information technology but on how the instructor makes use of the IT (Collis, 1995). The important instructor characteristics affecting e-learning success are IT competency, teaching style, attitude, and mindset (Webster \& Hackley, 1997). These should be expressed by effectively managing an LMS-based course and by using and encouraging feedback and two-way communication with students.

The next to be emphasized is willingness to adopt new technology (Abrahams, 2010). The adoption of educational technology is a complex issue; often instructors' pedagogical conceptions and values do not include using ICT in educational settings even if technology does not constitute any difficulty for them (Steel, 2009). Consequently, ubiquitous implementation of e-learning is limited by the absence of a holistic view of what should be done to make it effective and resistance to change amongst academic staff (Blin \& Monro, 2008; Keaster, 2005). Personal innovativeness and its antipode computer anxiety are therefore another challenge that may be critical for the success of LMS. Personal innovativeness in an information technology context is an individual's attitude reflecting a tendency to experiment with and to adopt new information technologies independently of the communicated experience of others (AlBusaidi \&Al-Shihi, 2012a). This is often difficult for academics for various reasons: lack of experience, skills, and technological mindset (Watts, 2007).

Adopting this new approach to education would require another considerable investment - time. Although one of the main goals of ICT in education is to speed up the process, many scholars underline that continual management of the e-course makes instructors' work very time consuming (Abrahams, 2004; Gillard, Bailey, \& Nolan, 2008).

Another important issue is the effectiveness of learning management systems which can be analyzed through several parameters: the extent to which LMS is used by stakeholders and their satisfaction (Naveh, Tubin, \& Pliskin, 2012).

According to recent research, the following factors influence student satisfaction with learning management systems: course content (Selim, 2007), perceived usefulness 
(Sun, Tsai, Finger, Chen, \& Yeh, 2008), perceived enjoyment, computer literacy (Liaw, Huang, \& Chen, 2008). On the other hand, instructors' satisfaction is impacted by technology experience and personal innovativeness (Al-Busaidi \&Al-Shihi, 2012b).

It is necessary to consider that every study in the area of e-learning has a specific focus prioritizing such different issues as technical, social, psychological, and pedagogical. These factors influence perceptions, adoption, and success of LMS in every specific case.

In our research we assume the following factors as the most important: administrative support, as the system is under implementation at the university and various organizational, structural, and infrastructural issues inevitably occur. To this we add the technological aspect, for the same reason, as the system is under construction. However, the results of our study reveal that the most influential factor appeared to be the human factor, namely perceptions and attitudes of two groups of stakeholders: students and teachers. These ideas are consistent with international studies in terms of identification of major areas of dissatisfaction and perceptions of quality online teaching and learning (Weaver, Spratt, \& Nair, 2008) and the importance of the role of teachers for the successful implementation of LMS (Steel, 2009). For many Russian universities using online learning systems is a new experience and we consider it relevant to study and highlight probable challenges.

\section{Research Questions}

The authors posed the following research questions :

1. What are the stakeholders' perceptions of the learning management system?

2. What is the connection between perceptions and usage?

\section{Hypotheses}

Having studied the corpus of works on LMS adoption and acceptance and the reports on the implementation of the system at HSE, we thus assumed:

1. Students and instructors at HSE have the necessary computer skills to embrace LMS and it will be easy for them to use it. If both groups, students and teachers, are confident computer users, we assume that there will be no resistance to using LMS.

2. Perception of LMS as an innovative and effective educational tool shall arouse students' and teachers' commitment to and interest in e-learning. To verify this, we analyzed the results of the survey with respect to the stakeholders' opinions of the following LMS parameters: 
- $\quad$ perceived usefulness (Davis, 1989);

- $\quad$ perceived convenience (Yoon \& Kim, 2007);

- $\quad$ perceived effectiveness (Lowerison, Sclater, Schmid, \&Abrami, 2006).

3. LMS is being introduced at HSE in addition to face-to-face learning. Thus, we hypothesize that the combination of these types of instructing shall lead to increased control over the students' academic progress.

4. Assessment is an important part of the educational process. Tests in LMS are an objective assessment tool and reflect the real picture of student achievement. Therefore, students may welcome taking final tests through LMS rather than taking an exam face-to-face with the teacher.

\section{Method}

The study aims at investigating the students' and teachers' perceptions of LMS and their commitment to it.

The target population consisted of students and instructors of HSE - Nizhny Novgorod campus. The survey was anonymous and respondent confidentiality was maintained. The procedure was as follows: The questionnaires in a paper format were administered at random to students in classes at the end of a lesson and then collected by a coordinator. All the students present agreed to participate in the survey. The instructors were approached in staff rooms and asked to fill in the questionnaire. Everybody present in staff rooms at the moment agreed to complete the questionnaire. The data were entered in computer programmes (MS Excel, MS Word) and then processed.

Two separate questionnaires were designed for students and teachers. The questionnaires contained closed and open questions as well as questions based on a 3point scale (2-poor, 3-average, 4-good).

One questionnaire was administered to bachelor and master students from the Faculties of Economics, Management and Business Informatics. The sample consisted of 109 students. The demography was as follows: $25 \%$ of them were men, $75 \%$ were women. The age of students was 18-21.

The questionnaire for students consisted of two parts. The first part was offered to students irrespective of their exposure to LMS to find out if they had heard about or had used LMS at least once. Both groups were asked about their perceptions and attitudes to LMS. After that. those who had the experience of working with LMS were given the second part of the questionnaire aimed at getting students' feedback on the system.

Another questionnaire was administered to instructors. Its purpose was to get information about teachers' perceptions and attitudes and their willingness to introduce 
the system into the learning and teaching process. Twenty-three teachers from different faculties participated in the survey. The demography of the teachers was $21.7 \%$ of men and $78.3 \%$ of women. The age of the teachers was between 30 and 60 .

\section{Organizational and Technological Environment}

Until recently, there has been little use of distant forms of learning in Russia which is often explained by the following reasons: unsatisfactory level of development of ICT and poor technological base. Today, however, preconditions for wider use of online learning are becoming more explicit. Moreover, technical capacities sometimes surpass the implementation of e-learning concepts and ideas by the Russian academia. At the same time, to successfully withstand the competition both in the domestic and international market of educational services, a modern university must incorporate the latest technologies in its educational programs and academic life. This encourages active involvement of all stakeholders and enables interaction among them.

Incorporating LMS into teaching and learning processes is a trend which is "becoming ubiquitous at universities around the world, adding a virtual dimension to even the most traditional campus-based institutions" (Coates, James, \& Baldwin, 2005). Being innovative, flexible, and pedagogically effective, LMS may provide support and enhance traditional ways of learning (Georgouli, Skalkidis, \& Guerreiro, 2008).

Being fully aware of these benefits, aiming to realize its innovative potential and increase competitiveness, HSE has been engaged in the institution-wide deployment of LMS at its four campuses. The system is functioning in a pilot mode and is subject to modifications required by students and instructors. The aim of the LMS project at HSE is to build a single information learning environment for the university. Its tasks are seen as

- to provide students and teachers with convenient tools to manage face-to-face and distant learning,

- to assist in mastering new learning methods,

- to support best practices of using ICT in teaching.

HSE aims at expanded LMS use, ensuring involvement and support from top management levels.

As of October, 1, 2012, 27\% of teachers and 43\% of students in all HSE campuses use LMS on a regular basis, the LMS diffusion thus reaching the critical mass point (Abrahams, 2010b); 6\% of all disciplines is supported in LMS. Training courses and seminars where new tools and features are presented to users regularly take place. Besides supporting, organizing. and administering disciplines, LMS is used to manage certain educational projects in HSE. An example of this is the experimental international English Language examination (in IETLS format) conducted in 2012 for 
more than 1,000 students (Ob itogakh UMD v 2011-2012 uch. godu., 2012). Therefore, the study of stakeholders' perceptions of LMS at HSE is needed to identify barriers and constraints as well as features to build on.

Among the four campuses, the HSE campus in Nizhny Novgorod chosen for the research is rated second (after Moscow) in terms of the number of teachers who use LMS (76 out of 213), third in terms of registered/ active LMS users among students (674 out of 3,036), and fourth in terms of the number of LMS-supported courses (33 out of $1,084)$.

\section{Findings}

\section{Hypothesis 1}

Verifying our first assumption we questioned students whether they are at ease with computers and the Internet. Students were asked a number of questions about their computer literacy, use of Internet, and frequency of usage. It turned out that the respondents were confident computer and Internet users; moreover, their use of the Internet was quite frequent: $98 \%$ reported using it every day and only $2 \%$ every other day. The time spent on the Internet is as follows: $47 \%$ of respondents spend more than 3 hours daily browsing the Internet, $26 \%$ devote 2 or 3 hours of their time, a few of the respondents (9\%) spend more than an hour a day, $18 \%$ say they are committed Internet users and they are always online. The results show that students find no difficulty browsing the Internet, and searching for any information they need for their studies.

We wondered what aims students pursued browsing the Internet so often. It is worth noting that the aims of using the Internet are various: 93\% use the Internet for information search and for communication with their peers, 57\% use it as help for writing their course and diploma papers, and only 19\% use the Internet for search of educational and learning programs (the total number does not make $100 \%$ as the respondents were free to choose any number of options). This is consistent with other studies which concluded that there was comparatively little growth in "educational" Internet use (Stationery Office, 2009).

Summing this up, we see that students at HSE are confident PC and Internet users and we can presume that LMS will present no significant difficulty for them.

\section{Perceived ease.}

At present, the number of students who have been exposed to LMS is 91 out of 109 questioned which means that $83.5 \%$ have used the LMS and $16.5 \%$ have only heard about it. It should be noted that out of 18 students who did not have any experience of using LMS, only one student said he would need some help while using the system. The rest were sure they would have no difficulty working with it. The majority of students 
(59\%) indicated they could cope with the system without any help. Eighteen percent of the respondents indicated they did not need any special LMS training courses and if they had any problems they could address their peers for help, and only $14 \%$ found it difficult to use.

As for teachers, they see computer literacy as part of their professional qualification. With respect to LMS, all the teachers are familiar with the system: 56\% of them have worked with LMS, 31\% intend to use it in future, and only $13 \%$ have no experience of using it.

Moreover, $79 \%$ of teachers point out that they have already completed the training course in LMS provided by the administration and are quite able to use the system. Only one respondent indicated that the system is difficult to operate. Nevertheless, among them the system is used by $40 \%$; the number of those who intend to use the system makes 33\%. The rest are undecided.

We can conclude that both groups of stakeholders have the necessary computer skills to embrace LMS and the system is perceived by the majority of them as easy-to-use. Nevertheless, not all teachers are engaged in using LMS and accordingly students do not have a chance to benefit from the system in their learning process. It means the problem is rooted not in the perceived complexity of the system but elsewhere.

\section{Hypothesis 2}

We presume that using this innovative system will arouse students' commitment to and interest in learning. Thus, we wondered how students perceive the system's convenience, usefulness, and effectiveness.

\section{Perceived convenience.}

Students were asked to evaluate the convenience of LMS based on a 3-point scale (2poor, 3-average, 4-good). The percentage of students selecting each response was as follows: $39 \%$ estimated the convenience of LMS as average, $36 \%$ of respondents indicated that the system is good, and $25 \%$ assess the system as poor. The mean score of convenience is 3.1. The convenience of the system is evaluated as slightly above average.

From the teachers' perspective, the convenience of LMS was perceived as average by the vast majority of respondents, $77 \%$, poor by $15 \%$, and the lesser part ( $8 \%$ ) evaluated the system as good. The mean score of convenience is 2.92 .

Analysing the results we should point out that although the mean scores nearly coincide across the groups, a significantly higher percentage of teachers perceive the convenience of the system as average, whereas students' answers are distributed more evenly among the options.

\section{Perceived usefulness.}

With respect to usefulness of LMS, $40 \%$ of students indicated its importance for uploading and storing materials, $34 \%$ of respondents consider that LMS makes the 
process of learning easier, $14 \%$ believe it fosters the learning process. The rest are undecided on the issue. As for teachers' perceptions of usefulness of LMS, 47\% of teachers claimed that the system is effective for uploading materials, $21 \%$ suppose that it makes the learning process easier, and 31\% think that it fosters learning (see Table 1). Teachers' and students' perceptions vary in many aspects of usefulness of LMS. Instructors misjudge the usefulness of different features of LMS, and they are unaware of the students' perception of LMS usefulness.

Table 1

Students' and Teachers' Perceptions of LMS

Options

$\begin{array}{cc}\begin{array}{c}\text { \% of respondents, } \\ \text { students }\end{array} & \begin{array}{c}\text { \% of respondents, } \\ \text { teachers } \\ 40\end{array} \\ 47\end{array}$

Important for uploading and storing materials

Makes the learning process easier

Fosters the learning process

Undecided

Teachers evaluated basic LMS parameters and mean scores were calculated, based on a 3-point scale (2-poor, 3-average, 4-good). Graphics were assessed as 3.13, interactive features as 3.26, storing and categorization of materials as 3.29. The lowest score was given to flexibility and customizability, 2.86. It may be explained by the fact that the system is still being developed.

Among the functions estimated, storing and categorization of material ranked the highest. The explanation lies in the analysis of activities that instructors undertake in LMS. Sixty-seven percent of teachers upload materials, 67\% publish home assignments, $44 \%$ use online grade book, and $44 \%$ test their students through LMS (the total number does not make $100 \%$ as the respondents were free to choose any number of options). In instructors' view, all these activities are supposed to contribute to the learners' involvement in the system and help ease their learning.

Communication being one of the hallmarks of higher education, we wondered how students view the communication through LMS. Only $8 \%$ agreed this tool is valuable, compared to $92 \%$ who report that they use corporate e-mail or social networks, which are more effective. It shows that LMS is not used by teachers as a means of facilitating collaboration and interaction with students and it does not help to enhance students' involvement in using it.

The results show that the attitudes of students and teachers to the parameters of the system are rather varied both inside each group of stakeholders and between the groups. Teachers and students are nearly unanimous with respect to LMS's importance for uploading and storing materials. It is worth noting that there is a considerable gap 
between their perceptions of LMS as a tool fostering the learning process and making it easier. The proportion of teachers who say that LMS enhances the learning process is two times higher compared to students, whereas a significantly higher number of students (as compared to teachers) view LMS as making the learning process easier.

\section{Perceived effectiveness.}

A significant majority of students (47\%) perceived the system as inconsistent with their learning purposes. Thirty-seven percent view the system as suitable for presenting and storing material, and $15 \%$ indicate that the system facilitates the perception of the material. Slightly over one third (34\%) of the respondents claim that the system makes the process of learning easier.

Effectiveness is assessed by teachers in terms of time investment, coverage of students, and speed of test results processing and grading. Teachers were to assess these factors on a 3-point scale (2-poor, 3-average, 4-good). Among the positive features of LMS teachers mentioned coverage of students (score is 3.6); the speed of test results processing and grading was given a score of 3.53.

The score given to the time-saving feature was only 2.57. From the teachers' perspective, work with LMS is very time-consuming: 68\% of teachers indicated such an aspect as time-consuming and none of them said that the LMS is a time-saving educational tool. It is quite natural, as teachers have to design the course, manage its web-site, prepare the content and tests, and monitor the whole process. It requires time and effort and often discourages teachers from using the system ( $50 \%$ of instructors were reluctant to use the system because of this reason).

As for students, their opinions about time investment vary. Twenty-five percent considered the system as time-saving, $19 \%$ as time-consuming (See Table 2 ).

Table 2

Time Investment

Options: LMS is

Time-saving Time-consuming
$\%$ of respondents, students

25

19
$\%$ of respondents,
teachers

0

68

Fifty-eight percent of teachers believed that it is not always reasonable to use LMS (for students the percentage is 49). However, when asked how many subjects should be available through LMS, $63 \%$ of students and $65 \%$ of teachers indicated they would like to have all subjects in LMS, $27 \%$ of students rejected the idea, $10 \%$ are still undecided. Thirty-five percent of teachers are now reluctant to accept the idea. 
We can presume that the majority of teachers and students are equally committed to using LMS and are therefore supposed to be interested in working with the system. However, when asked whether it was interesting or enjoyable for them to work with LMS, none of the students described the work with LMS as increasing interest in learning and only $2 \%$ perceive it as enjoyable, while teachers perceiving work with LMS as interesting or enjoyable is $10 \%$. Apart from this, $21 \%$ of teachers believe that LMS appeals to students and arouses their interest and commitment to the learning process. Instructors, therefore, misinterpret the students' interest in LMS which may lead to their being complacent as far as course design and management are concerned.

Our hypothesis that using LMS will increase a computer-literate academic user's commitment and interest had a two-pronged outcome: On the one hand, most users at HSE accept LMS and find it rather easy to use; that is, students welcome the idea that they can get easy access to all tasks and materials they cover in class at any time and any day. They can see home assignments, deadlines, all the necessary materials, and additional information which is very convenient for preparation. However, they do not consider it interesting, contradicting what teachers think on the subject.

\section{Hypothesis 3}

LMS by nature is transparent, so the progress and achievement of any student can be viewed by any LMS user, which makes students more concerned about the value of their contributions and grades received through the system. HSE has a system of ratings which are published on the corporate site and available to users. Being ambitious and striving to be the best, a lot of students place a great value on their online image and rating within the system. That is why their results in LMS are of vital importance for the whole picture.

LMS is supposed to be a valuable tool in assessing students' individual progress and measuring their achievements. We can presume that using LMS will help to increase control of students by the teacher.

Students were questioned whether LMS was effective as a control tool of the knowledge they received. The results showed that nearly half of the students (47\%) reported that LMS does not give a real picture of their academic achievement, 36\% indicated it is possible to cheat on the system by consulting the Internet, $26 \%$ believed in the effectiveness of LMS, and 15\% thought it is easier to exert control using LMS. The main aspect which the respondents emphasized with respect to the effectiveness of LMS is that it permits teachers to test students' knowledge within a limited time frame. However, an increase in control using LMS was indicated by only $32 \%$ of the respondents, while 58\% claimed the opposite. They felt that teachers' control of their learning process had decreased.

We see that using LMS for testing students' knowledge is perceived by quite a few students (43\%) as not always reasonable as you can get the wrong picture. Teachers, on their part, are convinced that using LMS in addition to face-to-face learning increases the teacher's control over the learning process of students (45\%), or are undecided on 
the point. It shows the discrepancy between teachers' and students' perceptions of LMS as an effective control of academic progress and achievement (See Table 3).

Table 3

LMS as an Assessment Tool

Options

Control increased

Control decreased
$\%$ of respondents, students

32

58
$\%$ of respondents, teachers 45

Undecided

LMS is not viewed by the majority of students as an effective tool in managing their learning process. Nearly $60 \%$ of students feel a lack of control from teachers when working with LMS; we can suggest that teachers rely too much on LMS for the control of students' progress by uploading different tests. Students might have an impression that teachers delegate part of their responsibilities to the online system and make themselves redundant, which is in line with other studies (Blin \& Monro, 2008). At the same time, according to the analyses of the teachers' answers, we see that although $45 \%$ stated that control increased, the bigger part had no opinion on the point. It means that they have the wrong picture of their LMS use as an effective assessment tool which is not the case in the eyes of the students.

\section{Hypothesis 4}

Students at HSE are very concerned about the assessment of their academic progress. Learners expressed their opinions about the possibility to get a higher grade through LMS and gave their reasoning. Forty-one percent said it is possible to get a better grade because of the system's unbiasedness. Yet, 59\% believed it is impossible because the grade will be less objective. As for teachers, their opinion was somewhat different. Thus, $44 \%$ claimed that it is possible to get a higher grade which is consistent with the students' opinion. But only $25 \%$ believed that it is impossible to get a higher grade through LMS than otherwise (See Table 4). 
Table 4

Objectivity of Grades through LMS

Options

It is possible to get a higher grade

It is not possible to get a higher grade Undecided
$\%$ of respondents, students

41

59

0
\% of respondents,
teachers 44

25

31

From their experience, most teachers did not view tests through LMS as an objective evaluation tool of students' progress. Sixty percent of them believed that students can get some assistance through the Internet or their peers. But 31\% of teachers saw the positive side of doing online tests thanks to the possibility of generating individual tests for learners. Still, they should not limit themselves to designing and uploading tests, but make use of interactive activities and other benefits which can be provided by this valuable learning tool.

It is evident that students would hardly prefer taking final tests through LMS rather than having face-to-face interaction with teachers. When asked how they would prefer to take their final tests and the reason, they gave the following answers: $33 \%$ wanted to see the teacher's reaction to their answer, $46 \%$ indicated that it is more pleasant for them to communicate with a person rather than a machine (67\% of instructors chose the same option), $46 \%$ hoped to correct their answer seeing the reaction of the teacher. However, the smaller part of teachers and students would like to use LMS, giving the following reasons: $16 \%$ of students would like to use LMS motivating their choice by psychological factors, for $13.7 \%$ LMS was less stressful, 12\% believed LMS helps to better focus on the task, $15 \%$ said it is easier to cheat. (The whole number does not make $100 \%$ as students were free to use any number of options.) In the instructors' opinion on the subject, LMS allowed them to conduct the exam faster (17\%) and to follow the prescribed format (11\%). Our hypothesis that LMS would be preferred by both groups of stakeholders as an assessment tool was not confirmed.

Students' grades are published in the online grade book which is available for LMS users. Students were asked their opinion about the online grade book. It was as follows: $35 \%$ were positive about it, $24 \%$ liked the idea of having their grades online to be able to follow their progress, $27 \%$ were indifferent, and $14 \%$ had a negative feeling of exposing their marks online, and they disapproved of the idea of their grades being available for everybody to see. Teachers had their own opinion about using grade book, their main concern being that it was not always appropriate to expose all grades in LMS (43\% of instructors indicated this issue); the second one is that it is time-consuming (36\% believe so); and another problem is that the grade book was inconvenient for using ( $14 \%$ 
chose this answer). However, $24 \%$ valued the opportunity to see students' progress dynamically.

To sum up, we can conclude that grade book is an integral part of LMS and that students are more eager to monitor their academic progress through their grades being published online conversely with teachers. Therefore, more research is required as to what influence grade book has on students' willingness to adjust their learning efforts to the desired results.

\section{Conclusions}

The idea of using LMS in classroom settings is to facilitate learning and enhance students' commitment and involvement as well as learning outcomes. However, it is too early to claim that teaching and learning practices at HSE are being transformed with the help of LMS.

The analysis showed that both groups, students and teachers, are at ease with computers and using LMS is not perceived as presenting any significant difficulty for them. It is a vital prerequisite as user perceptions are important for the success of the system, however not all learners perceive it as user-friendly. Moreover, for a number of students perceived ease of use of LMS does not imply its usefulness as a learning tool.

Nearly the same number of students and instructors favor having all subjects available in LMS. At the same time, they are not completely satisfied with the convenience of the system.

Perceptions of students and teachers coincide in terms of its usefulness as a bank of course materials. As for using other tools such as testing, doing tasks online, and communication activities, not all students express the desire to use LMS. One of the explanations can be that students are used to face-to-face learning and prefer this for their learning process.

The opinions of both groups differ with respect to the system usefulness, appropriacy, and interest for the students. Teachers' perception of LMS being interesting for students to use did not find its confirmation in the study. Most frequently used LMS tools, such as testing and grading, are also viewed differently by teachers and students. J udging by students' perceptions of the grades received through LMS, some of the students do not trust the objectivity of the system and are not inclined to be assessed through LMS. They do not really view it as a true reflection of their academic progress. Other students perceive the system as a more objective tool of assessing their achievement and would like to have a chance to get a higher grade for their tests or other assignments. At the same time, for teachers the situation here is somewhat controversial. On the one hand, a number of teachers rely too much on LMS, viewing it as an additional tool of students' academic achievement. As a result, some students feel a lack of control of their progress and become less involved. On the other hand, quite a few teachers have a similar 
opinion as students that the system does not show an objective picture of students' progress and believe these results can hardly be trusted. Teachers seem to either overestimate or underestimate the rigour and objectivity of LMS.

Having analysed the issues related to LMS adoption and use at HSE and recognizing the importance of its successful implementation, we conclude the emphasis should be laid on the human factor. Educators should be a driving force of innovation and bring university education to the next level. How teachers use the system depends on their involvement and belief in the effectiveness of this learning tool. Their commitment could translate into developing valuable online pedagogies and training materials thus engaging learners in the process of using the system to their own advantage. How enthusiastic and engaged teachers with an e-learning mindset could inspire students to embrace LMS requires further research. 


\section{References}

Abrahams, D. (2004). Technology adoption in higher education: A framework for identifying and prioritising issues and barriers to adoption (Doctoral thesis). Cornel University, USA.

Abrahams, D. (2010). Technology adoption in higher education: A framework for identifying and prioritising issues and barriers to adoption of instructional technology. J ournal of Applied Research in Higher Education, 2(2), 34-49.

Al-Busaidi, K., \&Al-Shihi, H. (2012). Key factors to instructors' satisfaction of learning management systems in blended learning. J ournal of Computing in Higher Education, 24, 18-39.

Alfadly, A. A. (2013). The efficiency of the "Learning Management System (LMS)" in AOU, Kuwait, as a communication tool in an e-learning system. International J ournal of Educational Management, 27(2), 157-169.

Almarashdeh, I., Sahari, N., Zin, N., \&Alsmadi, M. (2011). Acceptance of learning management system: A comparison between distance learners and instructors. Advances in Information Sciences and Service Sciences, 3(5), 1-9.

Benigno, V., \& Trentin, G. (2000). The evaluation of online courses. J ournal of Computer Assisted Learning, 16(3), 259-270.

Blin, F., \& Monro, M. (2008). Why hasn’t technology disrupted academics' teaching practices? Understanding resistance to change through the lens of activity theory. Computers \& Education, 50, 475-490.

Boeker, M., \& Klar , R. (2006). E-learning in the education and training of physicians. Methods, results, evaluation. Bundesgesundheitsblatt - Gesundheitsforschung Gesundheitsschutz, 49(5), 405-411.

Coates, H., J ames, R., \& Baldwin, G. (2005). A critical examination of the effects of learning management systems on university teaching and learning. Tertiary Education and Management, 11, 19-36.

Collis, B. (1995). Anticipating the impact of multimedia in education: Lessons from the Literature. Computers in Adult Education and Training, 2(2), 136-149.

Davis, F. (1989). Perceived usefulness, perceived ease of use and user acceptance of information technology. MIS Quarterly, 37(3), 319-340.

Freund, Y. (1988). Planner's guide: Critical success factors. Planning Review, 16(4), 20 25. 
Georgouli, K., Skalkidis, I., \& Guerreiro, P. (2008). A framework for adopting LMS to introduce e-learning in a traditional course. Educational Technology \& Society, 11(2), 227-240.

Gillard, S., Bailey, D., \&Nolan, E. (2008). Ten reasons for IT educators to be early adopters of IT innovations. J ournal of Information Technology Education, 7, 21-33.

Graf, S. (2007). Adaptivity in learning management systems focusing on learning styles (Ph.D. dissertation). University of Technology , Vienna, Austria. Retrieved from http://sgraf.athabascau.ca/publications/PhDthesis_SabineGraf.pdf

Keaster, R. (2005). Distance education and the academic department: The change process. Educause Quarterly, 28(3), 48-55.

Liaw, S., Huang, H., \& Chen, G. (2008). Surveying instructor and learner attitudes toward e-learning. Computers \&Education, 49, 1066- 1080.

Lin, B., \& Hsieh, C. (2001). Web-based teaching and learner control: A research review. Computers and Education, 37(3-4), 377- 386.

Lowerison, G., Sclater, J ., Schmid, R., \&Abrami, P. (2006). Student perceived effectiveness of computer technology use in post-secondary classrooms. Computers \& Education, 47(2006), 465- 489.

Mijatovic, I., Cudanov, M., J ednak, S., \& Kadijevich, D. (2012). How the usage of learning management systems influences student achievement. Teaching in Higher Education. Retrieved from http:/ / dx.doi.org/ 10.1080/ 13562517.2012.753049

Naveh, G., Tubin, D., \& Pliskin, N. (2010). Student LMS use and satisfaction in academic institutions: The organizational perspective. Internet and Higher Education, 13, 127- 133.

Naveh, G., Tubin, D., \& Pliskin, N. (2012). Student satisfaction with learning management systems: A lens of critical success factors. Technology, Pedagogy and Education, 21(3), 337-350.

Ob itogakh UMD v 2011-2012 uch. godu. (2012). Retrieved from http:// www.hse.ru/ org/hse/aup/ eduprocess/report UMR

Papp, R. (2000). Critical success factors for distance learning. Americas Conference on Information Systems, Long Beach, California, USA, 18(43).

Selim, H. (2007). Critical success factors for e-learning acceptance: Confirmatory factor models. Computers \& Education, 49, 396- 413. 
Soong, B., Chan, H., Chua, B., \& Loh, K. (2001). Critical success factors for on-line course resources. Computers \& Education, 36(2), 101- 120.

Steel, C. (2009). Reconciling university teacher beliefs to create learning designs for LMS environments. Australasian J ournal of Educational Technology, 25, 399420 .

Sun, P., Tsai, R., Finger, G., Chen, Y., \&Yeh, D. (2008). What drives a successful eLearning? An empirical investigation of the critical factors influencing learner satisfaction. Computers \& Education, 50, 1183- 1202.

Stationery Office. (2009). The learning revolution white paper. London: Department for Innovation, Universities and Skills [DIUS].

Volery, T., \& Lord, D. (2000). Critical success factors in online education. The International J ournal of Educational Management, 14(5), 216- 223.

Watts, N. (n.d.). Bringing online learning to a research-intensive university. eLearn Magazine. Education and Technology in Perspective. 2007. Retrieved from http:// elearnmag.acm.org/ featured.cfm?aid=1291534

Weaver, D., Spratt, C., \& Nair, C.S. (2008). Academic and student use of a learning management system: Implications for quality. Australasian J ournal of Educational Technology, 24(1), 30-41.

Webster, J ., \& Hackley, P. (1997). Teaching effectiveness in technology-mediated distance learning. Academy of Management J ournal, 40(6), 1282- 1309.

Yoon, C., \& Kim, S. (2007). Convenience and TAM in a ubiquitous computing environment: The case of wireless LAN. Electronic Commerce Research \& Applications, 6(1), 102-112.

\section{Athabasca University $\mathbf{a}$}

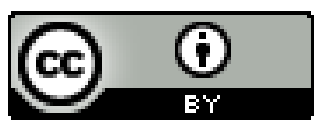

